Editorial

\title{
The Fragile Body in the Functional City: An Editorial
}

\author{
Matthias Drilling ${ }^{1, *}$ and Fabian Neuhaus ${ }^{2}$ \\ ${ }^{1}$ School of Social Work, University of Applied Sciences and Arts Northwestern Switzerland, 4132 Muttenz, Switzerland; \\ E-Mail: matthias.drilling@fhnw.ch \\ ${ }^{2}$ School of Architecture, Planning and Landscape, University of Calgary, Calgary, T2N 1N4, Canada; \\ E-Mail: fabian.neuhaus@ucalgary.ca \\ * Corresponding author
}

Submitted: 8 April 2019 | Published: 18 June 2019

\begin{abstract}
Changing circumstances force planning to re-define its role as a driving function shaping our cities today. One of the significant challenges to the century-old tradition of planning comes from the ageing population. The demand to age in place and its associated conditions particularly require renewed attention. This is, however, not an isolated and partisan topic, but speaks to the changing circumstances and highlights the dramatic shortcoming of a performance-oriented and segregationof-function-driven approach; one that is remnant of the early days of the planning discipline, but is still very much alive today. What has the discussion around ageing and the city brought up, and where are we headed? Two significant aspects are the body and moving away from a performance-oriented interpretation thereof, as well as a rethinking of participation not just as an information exercise, but as a co-design practice.
\end{abstract}

\section{Keywords}

agency; ageing; ageing in place; planning; social work; urban design

\section{Issue}

This editorial is part of the issue "The City, Aging and Urban Planning", edited by Matthias Drilling (University of Applied Sciences and Arts Northwestern Switzerland) and Fabian Neuhaus (University of Calgary, Canada).

(C) 2019 by the authors; licensee Cogitatio (Lisbon, Portugal). This article is licensed under a Creative Commons Attribution 4.0 International License (CC BY).

\section{Introduction: Technologies}

Extensive change is underway that is transforming the state-society relationship. This is highly visible in the politics of democracies around the world but, simultaneously, in the everyday lives of individuals on the streets. These shifts do not play out on a single scale but crisscross the network of urban centres and simultaneously touch on territories and people's lives in a multitude of ways. Planning as both a scientific activity and a practice is enveloped in this shift. Madanipour, Hull, and Healey (2001, p. 25) argue that planning "has to define its role, as well as its area of engagement to be distinctive from those of other actors. The pressure is such that if it does not, it could either be dissolved or become marginalised." Their analysis focuses specifically on governance, place, and territory. The shift, however, also includes citizens whom, as part of the change, have been transformed into a much more sophisticated populace, concerned with sustainability, the environment, and accessibility. This leads to an increased demand for better services and more participation. At the same time, the population is less responsive to traditional forms of social coherence and control. As part of these transformations, excluded groups have found a stronger platform within these changes to advocate for their needs. In the city, as a generational project, the ageing population plays a key role and the question of how to better serve their changing needs is pressing. But how does the built environment respond to the needs of an ageing population? Can planning, while being under pressure and searching for an identity, respond to a call for increased spatial referencing and engaging participation?

Technology is a big part of planning in many ways, not least because planning itself can be considered a technology. The functional city (van Es et al., 2014) rebranded 
the city as a high-tech apparatus to try and lift it out of what was considered a chaotic state (Hall, 1988). The city as an arrangement was then to be considered under pure aspects of logic and truth, universal truth. The implemented conceptual structure was based on hierarchy and sequential order as a top-down structure. The heavy focus on mechanic and machine analogies produced an image of a functioning city in the sense of an apparatus.

The same attitude was applied to the needs and requirements of the city's inhabitants. The ergonomic movement (Nussbaumer, 2014) delivered the requirements based on the mechanics of the human body. As Siegfried Giedion writes in his essay, "The Assembly Line and Scientific Management" (Giedion, 2007, p. 98), the ability, functioning, and performance of the human body in relation to its environment became the key to participation. To be part of a functioning city, citizens were required to be in possession of a functioning body.

Initially, overall performance was mainly important during the planning stage of the functional city. Facts in the form of numbers were used to direct development and design efforts. This quickly started to spread to the operation and claimed functions of the city. Performance criteria analysis of existing cities and working parts of the city became a trade of planners. Ultimately, the built environment came down to the abstract format of numbers, good numbers and bad numbers. Caught in the middle were, and still are, citizens. The belief that the city can be optimized and streamlined through analysis is more prevalent today than ever.

There was critical turn in urban planning after observing the large number of elderly people who were highly affected by exclusion processes. Scholars have collected data on two scales: on the city as a collection of individual status (finances, contacts, health, etc.), and on the city as a stage on which collective exclusion processes become visible (for example, when older people are driven out of places by younger groups). Studies that focus on the life situation of the elderly emphasise that exclusion processes at that stage of life are, above all, accompanied by a loss of independence and freedom. By withdrawing from the labour market, older people are suddenly dependent on standardised services, the quantity and quality of which are determined first and foremost by the state: transfers (especially old-age pensions and additional benefits), public transport, housing, and living environments. Older people with a low level of education and therefore low previous earnings, sick people, and widowed pensioners, in particular, are affected by those exclusion processes and these effects intensify when the neighbourhood in which these people live is itself considered to be disadvantaged. Buffel, Phillipson, and Scharf (2013) identified predictors of exclusion risks in old age in relation to the urban scale: (1) the duration of living in the neighbourhood and in the apartment since retirement, (2) trust in supportive neighbourhood relationships, (3) the frequency of relocation in the course of one's own life, and (4) the emotional ties to the neigh- bourhood. Older people should never withdraw from their living environment, as it results in a life that is concentrated on the home. In old age, this can be very difficult to reverse, thus negatively affecting the quality of life in the long term. In this respect, exclusion processes for older people have direct (for example, relocation due to displacement, lack of sense of security) or indirect (withdrawal into one's own home) socio-spatial consequences.

\section{Perceptions}

The city is, therefore, neither a functionalistic container (for example, a neighbourhood, a housing estate, a flat) where seniors live, nor is it a technical complication requiring sophisticated performance tools (as provided by the age-appropriate design of buildings, streets, spaces). Urban space forms and shapes itself along perceptions and attributions, filled with meanings that can run transversely to objective concepts such as life situations, milieus, or age groups: "Places are the context in which we live, settings, to which we feel attached but which also shape our experience of social processes, such as the provision of health care, the process of ageing, or social and economic restructuring." (Wiles, 2005, p. 101)

These different understandings led to the conclusion that dwelling is, above all, socially constructed: "The application of the theory of social space provides illuminating perspectives of how daily life is practised by older people as well as the meaning the space represents." (Wiles, 2005, p. 837) Petersen and Warburton (2012) describe old-age residences as places of segregation and ageism. In their study, they focused on how professional actors conceive of representations of space in the planning process of such complexes. They found that the ageing person: (1) is constructed according to his or her need for help, (2) does not appear in the process of planning, (3) is favoured as a single person, (4) is marketable, and (5) is homogenised by the absence of any differentiation. "Although many professional stakeholders show respect for older people, their work knowledge is made up of assumptions, generalisations, and commonplace euphemisms." (Petersen \& Warburton, 2012, p. 80)

In this context, Rudzitis (1984) refers to the emergence of "geriatric ghettos" in cities. His leading question about "how and why society and its institutions are organized in the way they are" led him to the thesis that these ghetto formations were driven primarily by the construction of inner-city seniors' homes and social housing, and that this resulted in older people remaining behind: the spatial concentration of the older population, mostly disguised as a voluntary decision, was nothing but a perfidious form of exclusion. Restricted mobility, coupled with the few existing social infrastructures on site, the fear of crime, and the low social capital in the neighbourhoods, perpetuated the processes of segregation. Rowles (1978) posed a similar argument in Prisoners of Space, in which he examined the housing situation of older people and focused on their everyday practice. Basic elements of the 
life-world of elderly people, including the physical limitations and associated radius of action ("action"), the images of the living environment designed by the elderly themselves ("mental maps/orientation"), the emotions associated with the neighbourhood ("feelings"), as well as the belief that everything could be different from what an old person can imagine at the moment ("fantasy") all led to a spatial consolidation of elderly people with increasing age. This is significant since negative restrictions are increasingly less compensable with satisfaction in one's "own four walls" (Golant, 1982).

\section{Should Planning Remain Neutral?}

Living cannot be limited to its functional character of providing accommodation. Rather, it is the attribution of meaning to housing in the context of individual and collective perceptions and expectations, as well as the relevance of these in the context of generational relationships and concrete artefacts of housing (seniors' homes, housing estates, neighbourhoods), that enables us to distinguish between inclusive and exclusive effects of planning measures.

By remaining ambiguous about these details, planning does not commit to specifics in order to accommodate these needs. Furthermore, planning addresses specialists with this sort of language, experts who are ready to interpret "accessible" not in a broad, but in a very specific sense. At this level, overall planning remains neutral to the demand for age-appropriate environments. The message that comes across is that by building "good" cities, planning caters to everybody. Of course, "good" cities are contested, just like planning as a discipline is contested. Urban development as a moneymaking machine requires planning to enable these activities. It makes a distinction between the free market as a capitalist system and state intervention. This was, for example, discussed by David Harvey as a conflict over "production, management and use of the urban built environment." (Harvey, 1976, p. 265) Capitalism both demands and rejects state intervention. Campbell, Fainstein, and Foglesong (2003) point out that "the market system cannot meet the consumption needs of the working class in a manner capable of maintaining capitalism." This leads to a division between individualised planning by the market and collective planning through the state. However, the main subject of planning, in a physical sense, is the land. Harvey (2009, p. 157) describes it as "uniqueness of land as a commodity," highlighting the fact that it is not transportable nor is it infinite or transferable. There is only one land to plan for. To serve both sides, the market and the state, planning remains ambiguous.

\section{Conclusion: Where to Go}

What we are seeing in current practices is that planning has not let go of the functional focus on how cities are conceived. The current driving parameter is performance and its implied increase and optimisation are barriers to age-friendly cities and ageing in place more specifically. Much of the discussion still builds around the notion of performance. The current discussion still asks for "walkable neighbourhoods", "good street design", "effective urban spaces", "public-oriented plazas", or even "healthy cities".

This is an issue for the ageing population in particular, as outlined in the discussion above. Care homes are only a solution in some cases, but across the board, people want to remain at home for as long as possible and be actively engaged in their communities. This represents the most substantial challenge to the urban planning practice, something that other pressing topics over the past century, such as poverty, housing, race and gender discussion, or homelessness have not managed to achieve.

Cities are very slow-transforming artefacts and change will not happen overnight unless it is shared, unless activism and collective participation push an agenda for change. Two topics discussed previously, as suggested by Buse, Nettleton, Martin, and Twigg (2017, p. 8), can help push for change in approaches to the body by moving away from performance towards inclusion and secondly by shifting from a provision of service to co-creation and participative design. Performance has to be secondary; the primary goal of planning has to be getting together, sharing, and co-creating. There are emerging practices in planning and urban theory. In her work, Oldfield (2018), for example, reflects on how to build urban theory as a collective practice (Oldfield, 2018, p. 229). Her work includes scholars, planners, and communities. Fuchs (2010, p. 42) has presented some ideas for a foundation, more specifically in relation to PCSIS (participatory, cooperative, sustainable information society), by insisting on a dialectic system. The challenge that an ageing population poses for planning and our cities, in general, should be a welcome one. In addition to all of the benefits in regard to physical infrastructure accessibility, inclusion, and marginalisation, this has the potential to refocus the discipline and open up a new avenue of cross-cutting dialogue that instils a new identity, a shared identity.

\section{Acknowledgments}

Many of the arguments in this article have arisen in the context of the COST Action CA15122 ROSEnet, supported by COST (European Cooperation in Science and Technology). The authors thank their colleagues for the fruitful discussions.

\section{Conflict of Interests}

The authors declare no conflict of interests.

\section{References}

Buffel, T., Phillipson, C., \& Scharf, T. (2013). Experiences of neighbourhood exclusion and inclusion among 
older people living in deprived inner-city areas in Belgium and England. Ageing \& Society, 33, 89-109.

Buse, C., Nettleton, S., Martin, D., \& Twigg, J. (2017). Imagined bodies: Architects and their constructions of later life. Ageing \& Society, 37(7), 1435-1457.

Campbell, S., Fainstein, S. S., \& Foglesong, R. (2003). Planning the capitalist city. In S. Fainstein (Ed.), Readings in planning theory (2nd ed., pp. 102-107). Malden, MA: Blackwell Publishers.

Fuchs, C. (2010). Theoretical foundations of defining the participatory, co-operative, sustainable information society. Information, Communication \& Society, 13(1), 23-47.

Giedion, S. (2007). The assembly line and scientific management. In W. W. Braham, J. A. Hale, \& J. S. Sadar (Eds.), Rethinking technology: A reader in architectural theory (pp. 83-112). London: Routledge, Taylor \& Francis Group.

Golant, S. M. (1982). Individual differences underlying the dwelling satisfaction of the elderly. Journal of Social Issues, 38, 121-134.

Hall, P. (1988). Cities of tomorrow: An intellectual history of urban planning and design in the twentieth century. Oxford: Basil Blackwell.

Harvey, D. (1976). Labor, capital, and class struggle around the built environment in advanced capitalist societies. Politics \& Society, 6(3), 265-295.

Harvey, D. (2009). Social justice and the city. Athens, GA:
University of Georgia Press.

Madanipour, A., Hull, A., \& Healey, P. (2001). Introduction. In A. Hull \& A. Madanipour (Eds.), The Governance of place: Space and planning processes (pp. 1-15). Aldershot: Ashgate.

Nussbaumer, L. L. (2014). Human factors in the built environment. New York, NY: Fairchild Books.

Oldfield, S. (2018). In everyday city struggles: Collaborative research and its inspirations. In M. Grubbauer \& K. Shaw (Eds.), Across theory and practice: Thinking through urban research (pp. 223-230). Berlin: Jovis Verlag.

Petersen, M., \& Warburton, J. (2012). Residential complexes in Queensland, Australia: A space of segregation and ageism? Ageing \& Society, 32, 60-84.

Rowles, G. D. (1978). Prisoners of space? Exploring the geographical experience of older people. Boulde: Westview Press.

Rudzitis, G. (1984). Geographical research and gerontology. An overview. Gerontologist, 24(5), 536-542.

Van Es, E., Harbusch, G., Maurer, B., Pérez, M., Somer, K., \& Weiss, D. (Eds.). (2014). Atlas of the functional city: CIAM 4 and comparative urban analysis. Bussum: THOTH Publishers, gta Verlag.

Wiles, J. (2005). Conceptualizing place in the care of older people: The contributions of geographical gerontology. International Journal of Older People Nursing, 14(8), 100-108.

\section{About the Authors}

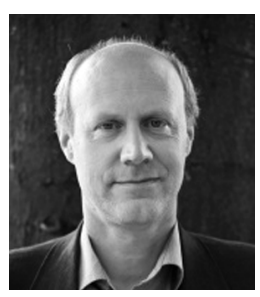

Matthias Drilling is Head of the Institute for Social Planning, Organizational Change and Urban Development at the School of Social Work, University of Applied Sciences and Arts Northwestern Switzerland. His research focuses on the future of cities and urban neighbourhoods, social sustainability, urban governance, and democratic and empowering approaches. He is a Management Committee Member of the EU-COST Action "Reducing Old-Age Social Exclusion: Collaborations in Research \& Policy" (CA 15122).

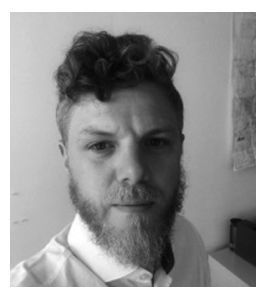

Fabian Neuhaus is Assistant Professor in Planning at the School of Architecture, Planning and Landscape, University of Calgary. He has received his PhD in urban planning from UCL. His research interests are temporal aspects of the urban environment. His research focuses on the topics of Habitus, Type, and Ornament in the sense of Activity, Technology, and Memory. He has worked with architecture, planning, and urban design practices in the UK and Switzerland as well as on research projects at universities in Switzerland, Germany, the UK, and Canada. He is the principal author at www.urbantick.org. 